\title{
Comparison of the shelf-life of commercial salad lettuces based on packaging types
}

\author{
Min-Sun Chang*, Jeong-Hee Kim, Jung-Soo Lee, Mehea Park, \\ Eun-Ha Chang, Yoonpyo Hong \\ Postharvest Technology Division, National Institute of Horticultural \& Herbal Science, Wanju 55365, Korea
}

\section{유통 중인 샐러드용 상추 종류별 포장형태에 따른 선도유지 비교}

\author{
장민선* · 김정희 · 이정수 · 박미희 · 장은하 · 홍윤표 \\ 국립원예특작과학원 저장유통과
}

\begin{abstract}
A comparison of the shelf-life of various lettuces (i.e., Ezabel, Butterhead, Pagero, mini Romaine, Caipira and red leaf lettuce) during storage was carried out based on different packaging types. More specifically, the Butterhead lettuce sample was packaged in a polyethylene terephthalate (PET) tray, while the Ezabel, Pagero, mini Romaine, Caipira and red leaf lettuce samples were packaged in polypropylene (PP) film. Changes in the sample weight loss, respiration rate, chlorophyll content, and visual quality were then investigated during storage at $10^{\circ} \mathrm{C}$. The Ezabel and Caipira samples exhibited the highest weight loss, whereas the Butterhead sample showed the lowest weight loss. Among the various lettuce samples, the chlorophyll content of the mini Romaine lettuce was the highest. In addition, the freshness of the Butterhead lettuce sample was maintained during 18 days at $10^{\circ} \mathrm{C}$, compared to $12 \mathrm{~d}$ for the Ezabel, Pagero, mini Romaine, and Caipira samples. These results therefore suggest that tray packaging was effective in maintaining the lettuce quality, while packaging in a PP resulted in leaf softening and discoloration. Larger leaf areas also resulted in longer shelf-life. The development of an optimal packaging for lettuce to ensure that freshness is maintained during storage is therefore necessary.
\end{abstract}

Key words : lettuce, packaging, freshness, quality, shelf-life

\section{서 론}

상추는 우리나라 대표적인 쌈채소로 국내 상추 재배면 적은 $3,387 \mathrm{ha}$, 총 생산량은 86,128 톤이며, 엽채류 중에서 는 배추, 양배추 다음으로 많은 비중을 차지하고 있다. 국내 잎상추의 경우, $60 \%$ 이상이 적축면과 적치마 상추이 며, $30 \%$ 는 청치마 상추, 이 밖에 청축면과 로메인 등 특수 상추가 $10 \%$ 정도 유통되고 있다(Jang 등, 2017). 잎은 녹색, 적색, 흑자색 등 다양하며, 육질이 연하고, 수분 함량은
$95 \%$ 정도로 비타민 A, B, C, E 및 다량의 철분을 함유하고 있어 영양가가 풍부하다(Jang 등, 2007).

상추는 주로 쌈용으로 이용되거나 연하고, 아삭아삭하 며 독특한 맛 때문에 샐러드 채소로도 널리 이용되고 있으 며, 그 종류로는 크게 엽형(loose-leaf type) 상추, 결구형 (head or crisphead type) 상추, 코스 또는 로메인형(cos or romaine type) 상추, 버터헤드형(butterhead type) 상추, 줄기 형(stem type) 상추, 그리고 라틴형(latic type) 상추 등 6가지 로 구별된다(Whitaker 등, 1974; Kristkova 등, 2008). 최근

*Corresponding author. E-mail : aeru@korea.kr, Phone : +82-63-238-6540, Fax : +82-63-238-6505

Received 18 November 2019; Revised 11 February 2020; Accepted 11 February 2020.

Copyright (c) The Korean Society of Food Preservation.

This is an Open Access article distributed under the terms of the Creative Commons Attribution Non-Commercial License (http://creativecommons.org/licenses/by-nc/4.0) which permits unrestricted non-commercial use, distribution, and reproduction in any medium, provided the original work is properly cited. 
웰빙 열풍과 함께 음식문화의 변화로 우리나라에서도 샐 러드용 상추 소비가 증가하면서 결구상추와 1990년도에 유럽에서 수입된 코스 및 로메인 상추도 육성되기 시작하 였다(Hong 등, 2007). 이에 소비자가 선호하는 상추 종류가 다양해지며 고급화를 추구하는 경향이 증가하고 있다.

그러나 상추와 같은 엽채류는 엽육 조직이 얇고, 수확 후 높은 호흡률 등으로 인한 급격한 품질 저하로 유통기간 중 주의를 요구하는 작물이다(Lee 등, 2005). 또한, 부적절 한 저장 및 유통조건으로 갈변, 이취, 물러짐 등이 발생하 는 단점이 있으므로(Chang과 Lee, 2017) 적정 선도유지 기술 개발이 필요하다. 일반적으로 상추 선도유지와 관련 하여 주로 잎상추 또는 결구상추에 대해서 저온저장과 포장(Jeong 등, 2003; Lee 등, 2006; Chang과 Lee, 2017)에 대한 연구가 보고되었고, 신선편이 로메인 상추에 대하여 열처리(Bae 등, 2016) 관련 연구가 보고되었다. 상추 종류 별에 대해서는 유전자원 및 유통품종 식별(Hong 등, 2013), 품종구분을 위한 표준품종 선정(Hwang 등, 2003), 선호도 조사(Kim 등, 2017) 등에 대한 연구는 이루어졌으나, 상추 종류별 저장 중 선도유지 비교에 대한 연구는 매우 미비한 실정이다.

따라서 본 연구에서는 유통 중인 상추 종류별 포장형태 에 따른 선도유지를 비교함으로써 저장 중 품질 저하 문제 점을 파악하고, 또한 소비자 요구에 맞는 고품질 상추의 신선도 유지에 효과적인 포장방법에 대한 개선점을 찾고 자 하였다.

\section{재료 및 방법}

\section{실험재료}

본 연구에 사용한 상추는 적상추, 이자벨, 버터헤드, 파
게로, 미니로메인, 카이피라 등 6 종류로 충남 논산에서 재배되어 2017년 10월에 수확하여 포장한 것을 사용하였 으며 전체적으로 외관 상태와 모양이 균일한 것을 선별하 여 시료로 사용하였다.

\section{포장형태 및 저장}

상추 포장은 Fig. 1과 같이 시중에 유통 중인 포장형태 그대로를 사용하였다. 적상추는 PP $40 \mu \mathrm{m}$ 필름 포장에 $1 \mathrm{~cm}$ 간격으로 미세천공이 있었고, 이자벨과 카이피라는 $\mathrm{PP} 30 \mu \mathrm{m}$ 필름 포장에 가운데 부분을 제외하고 전체적으 로 미세천공이 있었다. 파게로는 두께 $30 \mu \mathrm{m} \mathrm{PP}$ 필름으로 천공 $\varnothing 5 \mathrm{~mm}$ )이 4 개 있었으며, 미니로메인은 PP $40 \mu \mathrm{m}$ 필름으로 위와 아래 부분에 2 줄씩 미세천공이 있었다. 또 한 버터헤드는 뚜껑이 있는 PET 용기로 포장되어 있었다. 상추 종류별 각각 포장된 상추는 연구소로 이동하여 $10^{\circ} \mathrm{C}$ 저장고에서 약 18 일간 저장하였다.

\section{중량감소율 측정}

초기중량과 일정기간 경과 후 측정된 시료의 중량 차이 를 초기중량에 대한 백분율(\%)로 나타내었다.

\section{호흡률 측정}

상추를 $8.5 \mathrm{~L}$ 밀폐용기에 넣어 내부에 축적된 head space 기체 $100 \mu \mathrm{L}$ 를 gas-tight syringe로 취한 후 gas chromatography(GC 7890B, Agilent Technol., DE, USA)를 이용하여 $\mathrm{CO}_{2}$ 농도를 측정하였다. 이때 분석조건으로 column(HP-5, Agilent Technol., DE, USA) 온도는 $80^{\circ} \mathrm{C}$, 이동상은 5 $\mathrm{mL} / \mathrm{min}$ 유량의 $\mathrm{He}$ 을 사용하였으며, 검출기는 $\mathrm{TCD}$ 로 검출 온도는 $250^{\circ} \mathrm{C}$ 였다(Chang과 Lee, 2017).
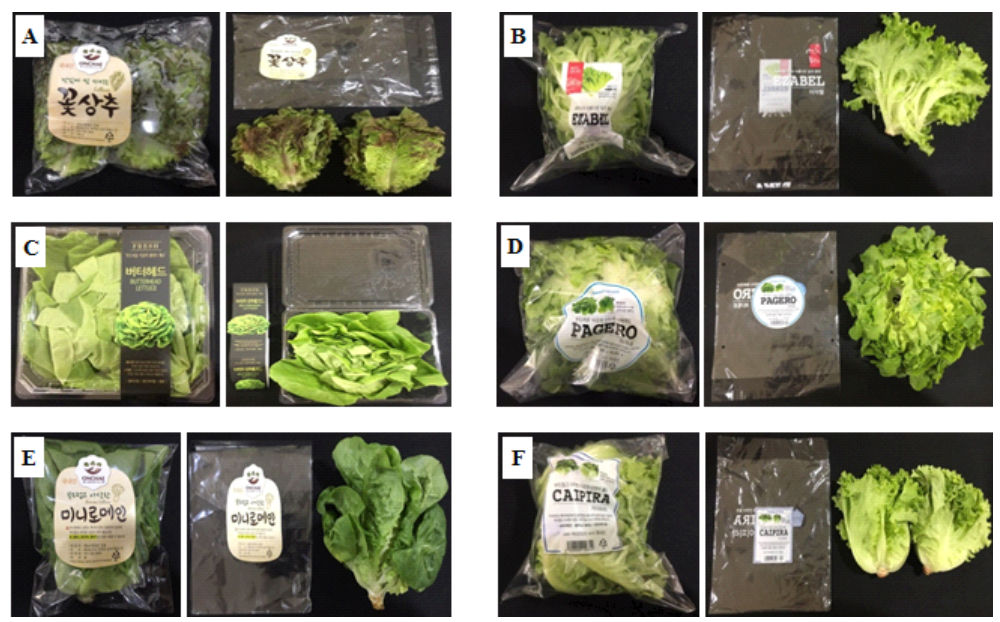

Fig. 1. Commercial packaging types for sale of lettuces.

(A), Leafy lettuce; (B), Ezabel; (C), Butterhead; (D), Pagero; (E), mini Romaine; (F), Caipira. 


\section{엽록소 함량 측정}

엽록소 함량은 적상추를 제외한 상추에 대하여 겉잎 1장을 제거한 후 초록부위에 대하여 엽록소계(soil \& plant analyzer development, SPAD-502, Minolta Co., Tokyo, Japan)를 이용하여 녹색정도에 따른 엽록소 함량변이를 측정하였다(Bark 등, 2015).

\section{통계처리}

결과의 통계처리는 SAS(Version 9.2, SAS Inc., Cary, USA) 프로그램을 사용하여 ANOVA 분석을 수행하였으 며, 평균간 유의차 검증은 Duncan's multiple range test 방법 으로 유의수준 $\mathrm{p}<0.05$ 에서 분석되었다.

\section{결과 및 고찰}

\section{중량감소율 변화}

상추 종류별 포장형태에 따른 저장 중 중량감소율은 저장기간이 경과함에 따라 전반적으로 증가하였으며(Fig. 2) 상추 종류에 따른 차이를 보였다. 전반적으로 적상추 $<$ 버터헤드 < 미니로메인 < 파게로 < 카이피라 < 이자벨 순으로 중량감소율이 높았으며, 비교적 잎이 넓은 형태보 다 잎이 좁은 형태의 상추에서 중량감소가 크게 나타났다. 저장 18 일째 적상추, 버터헤드, 미니로메인의 중량감소율 이 각각 $0.3 \%, 0.8 \%, 1.2 \%$ 로 나타난 반면, 파게로는 $4.0 \%$, 카이피라는 $8.7 \%$, 이자벨은 $13.1 \%$ 로 상추 종류에 따른 유의적인 차이를 보였다 $(\mathrm{p}<0.05)$. 중량감소율이 낮았던 적 상추와 미니로메인은 PP $40 \mu \mathrm{m}$ 필름 포장으로 $1 \mathrm{~cm}$ 간격 또는 필름 아래와 윗부분 2줄씩 각각 미세천공이 있었으 며, 버터헤드는 PET 용기 포장 형태였다. 그러나 중량감소

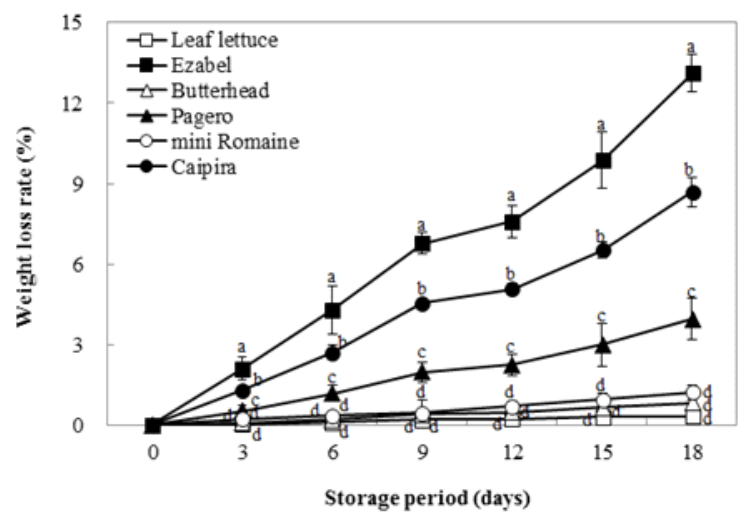

Fig. 2. Changes in the weight loss rate of lettuces by packaging types during 18 days at $10^{\circ} \mathrm{C}$.

$\square$, Leaf lettuce; $\boldsymbol{\square}$, Ezabel; $\triangle$, Butterhead; $\boldsymbol{\Delta}$, Pagero; $\bigcirc$, mini Romaine; O, Caipira.

Values represent the mean $\pm \mathrm{SD}(\mathrm{n}=5)$. Means with different letters are significantly different at $\mathrm{p}<0.05$.
율이 높았던 파게로, 카이피라, 이자벨의 경우 PP $30 \mu \mathrm{m}$ 필름 포장으로 파게로는 천공 $\varnothing 5 \mathrm{~mm}) 4$ 개, 카이피라와 이자벨은 전체적으로 미세천공이 있는 형태였다. 즉, 상추 잎이 좁으며 천공이 4개 또는 필름 전체에 미세천공이 있는 PP $30 \mu \mathrm{m}$ 필름으로 포장한 경우, 증산작용이 활발하 게 일어나 중량감소가 높은 것으로 나타났다. 또한, $\mathrm{PP}$ $30 \mu \mathrm{m}$ 필름은 PP $40 \mu \mathrm{m}$ 보다 얇아 내부와 외부의 기체투과 성이 활발하게 작용하여(Jeong 등, 2011) 중량감소율이 높 았다고 생각된다. 따라서 상추 형태적인 차이와 함께 포장 방법에 따른 차이 또한 중량감소에 영향을 미친다고 사료 된다. 일반적으로 채소작물은 생체중량이 $5-10 \%$ 줄어들 면 상품성을 상실하는 것으로 알려져 있는데(Chang과 Lee, 2017), 본 연구에서 중량감소가 가장 크게 발생한 이자벨 은 저장 9 일째 $6.8 \%$ 였으며 저장 18 일째에는 $13.1 \%$ 까지 증가하여 상품성이 가장 낮은 것으로 나타났다. 현재 시중 에 유통 중인 상추 포장형태는 종류별 특성을 고려하지 않은 형태로 저장 중 품질 저하가 쉽게 발생하였으므로 추후 상추 종류별 선도유지를 위한 최적 포장기술을 확립 할 필요가 있다고 판단된다.

\section{호흡률 변화}

상추 종류별 포장형태에 따른 저장 중 호흡률을 측정한 결과, 저장초기 호흡률은 $44.3-52.5 \mathrm{mg} / \mathrm{kg} \cdot \mathrm{h}$ 로 나타났으 며, 이후 $10^{\circ} \mathrm{C}$ 저장 직후 감소하였다가 저장 15 일 이후 다소 증가하는 경향을 보였다(Fig. 3). 상추와 같이 호흡이 왕성한 엽채류는 수확직후 상온에 방치될 경우 호흡 열이 증가하지만(In과 Kim, 2008) 본 연구에서는 $10^{\circ} \mathrm{C}$ 저장으로 호흡 열이 제거되어 저장초기보다 호흡속도가 다소 억제 된 것으로 사료된다. 저장 3 일째 버터헤드 호흡률이 22.9

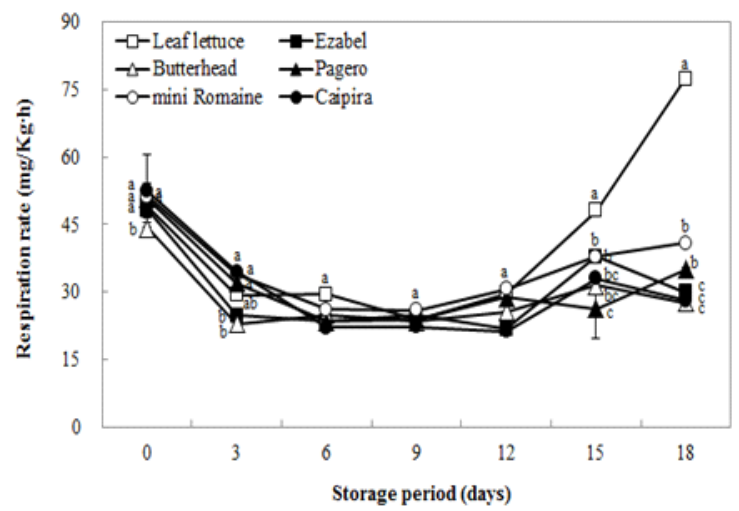

Fig. 3. Changes in the respiration rate of lettuces by packaging types during 18 days at $10^{\circ} \mathrm{C}$.

$\square$, Leaf lettuce; $\boldsymbol{\square}$, Ezabel; $\triangle$, Butterhead; $\boldsymbol{\Delta}$, Pagero; $\bigcirc$, mini Romaine; Caipira.

Values represent the mean $\pm \mathrm{SD}(\mathrm{n}=5)$. Means with different letters are significantly different at $\mathrm{p}<0.05$. 
$\mathrm{mg} / \mathrm{kg} \cdot \mathrm{h}$ 로 가장 낮았고, 카이피라는 $34.6 \mathrm{mg} / \mathrm{kg} \cdot \mathrm{h}$ 로 가 장 높았으며, 상추 종류에 따른 유의적인 차이를 보였다 $(\mathrm{p}<0.05)$. 저장 6-12일까지 상추 호흡률은 전반적으로 22.2

- $30.6 \mathrm{mg} / \mathrm{kg} \cdot \mathrm{h}$ 범위를 유지하였고, 상추 종류별 유의적 인 차이는 없었다. 저장 15 일 이후 상추 호흡률은 서서히 증가하는 경향을 보였으며, 특히 적상추의 호흡률이 저장 18 일째 $77.4 \mathrm{mg} / \mathrm{kg} \cdot \mathrm{h}$ 로 가장 높았고, 버터헤드는 27.7 $\mathrm{mg} / \mathrm{kg} \cdot \mathrm{h}$ 로 가장 낮았다. 또한 포장형태에 따른 호흡률 차이를 보였으며, PET 용기 포장 버터헤드 < PP $30 \mu \mathrm{m}$ 필름 포장 이자벨, 파게로, 카이피라 < PP $40 \mu \mathrm{m}$ 필름 포장 적상추, 미니로메인 순으로 호흡률이 높았다. 적상추를 제외한 모든 상추는 결구형태로 적상추와 같이 잎이 하나 씩 분리된 경우 호흡률이 저장 15 일 이후 급격히 증가하는 패턴을 보여 상추 형태에 따른 호흡률의 차이를 보였다.

\section{엽록소 함량 변화}

채소류의 주색소인 엽록소는 식물에 널리 분포되어있 는 천연 녹색색소로서 식물 세포내의 엽록체에 존재하여 채소 및 과일의 신선함을 나타내는 지표가 되는 것으로 알려져 있다(Ma와 Dolphin, 1999). 본 연구에서 상추 종류 별 포장형태에 따른 저장 중 엽록소 함량 변화를 $\mathrm{SPAD}$ 값으로 나타내었으며, 그 결과 상추 종류별 뚜렷한 엽록소 함량 차이가 있었다(Fig. 4). 저장초기 상추 엽록소 함량은 카이피라 $(21.8)<$ 이자벨 $(26.5)<$ 파게로 $(29.2)<$ 버터헤드 (33.0) < 미니로메인(42.1) 순으로 유의적으로 높았으며 $(\mathrm{p}<0.05)$, 저장기간이 경과함에 따라 다소 감소하였다. 일 반적으로 원예작물은 저장기간이 증가함에 따라 엽록소 손실에 의한 황화가 진행되어 $\mathrm{SPAD}$ 값이 감소하는데(Lee 등, 2007), 본 연구에서도 전반적으로 저장 중 엽록소 함량 이 감소하였고, 저장 중 상추 종류별 뚜렷한 차이가 있었

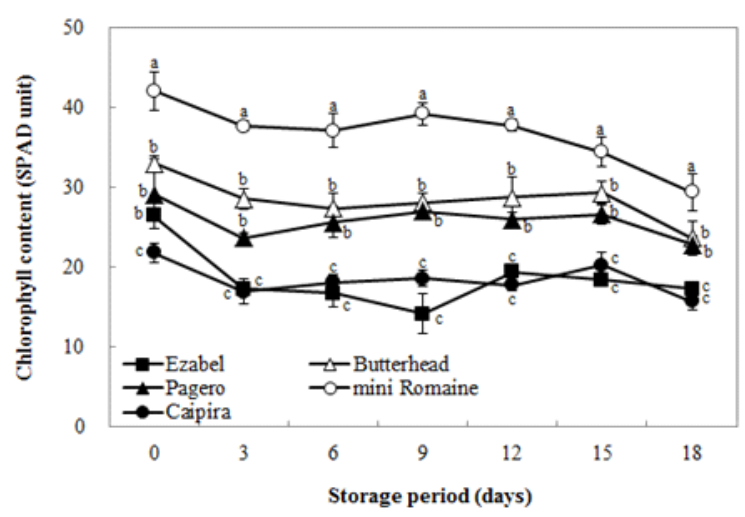

Fig. 4. Changes in the chlorophyll content of lettuces by packaging types during 18 days at $10^{\circ} \mathrm{C}$.

, Ezabel; $\triangle$, Butterhead; $\Delta$, Pagero; $\bigcirc$, mini Romaine; $\boldsymbol{O}$, Caipira. Values represent the mean $\pm \mathrm{SD}(\mathrm{n}=5)$. Means with different letters are significantly different at $\mathrm{p}<0.05$.
다. 이자벨과 카이피라, 그리고 버터헤드와 파게로의 엽록 소 함량이 비슷한 수준이었으며, 저장 3-15일 동안 이자 벨과 카이피라는 17.0 - 20.3, 버터헤드와 파게로는 23.7 29.4 범위를 보이며 변화폭이 적었다. 저장 18 일째 카이피 라(15.7) 및 이자벨(17.3) < 파게로(22.9) 및 버터헤드(23.7) < 미니로메인(29.4) 순으로 미니로메인은 다른 상추보다 엽록소 함량이 높았다. 이러한 로메인형 상추는 조직감과 향 또한 우수하여 소비자의 선호도가 높은 품목으로 최근 신선편이 제품으로도 많이 이용되며, 생산량이 증가하고 있다(Bae 등, 2016). 엽록소 함량은 상추 종류별 포장형태 에 따른 차이는 없었으며, 본연에 가지고 있는 엽록소 함량 에 따라 저장 중 감소하는 변화만 보였다.

\section{외관 변화}

저장기간이 경과함에 따라 상추 종류별 부패, 물러짐, 절단면 갈변 등 품질 저하 현상에 차이를 보였으며, 잎이 좁은 형태인 이자벨의 물러짐이 가장 심했고, 절단면 갈변 현상과 함께 중륵으로 물러짐이 이어지는 현상을 보였다. 또한, 이자벨과 비슷한 형태인 파게로와 카이피라 역시 물러짐 현상이 발생하였고, 잎이 넓은 버터헤드, 적상추, 미니로메인보다 품질 저하가 빨리 일어남을 알 수 있었다 (Fig. 5). 특히 버터헤드는 잎이 넓은 형태적 특성과 함께 $\mathrm{PP}$ 필름에 포장된 다른 상추들과 달리 PET 용기에 포장되 어 있어 용기 포장이 PP 필름보다 저장 중 품질 유지에 다소 효과적이었다고 판단된다.

본 연구에서 상추 종류별 포장형태에 따른 선도유지를 비교한 결과, 상추 잎 너비가 넓으며 용기 포장 한 경우 선도유지 기간이 길었고, 잎 너비가 좁을수록 증산작용이 활발하여 수분손실에 따른 중량감소 및 물러짐 현상이 심했다. 이러한 품질 저하 현상을 보완하여 저장성을 높이 고, 소비자 요구에 맞는 고품질 상추 저장을 위하여 종류별 맞춤형 포장기술이 확립될 필요가 있다고 사료된다.

\section{요 약}

상추 종류별 포장형태에 따른 저장 중 선도유지를 비교 하고자 연구를 수행하였다. 상추는 이자벨, 버터헤드, 파게 로, 미니로메인, 카이피라, 적상추 등 총 6종이었으며 시중 에 유통되는 포장형태 그대로 버터헤드는 PET 용기, 그 외 상추는 $\mathrm{PP}$ 필름으로 포장하여 $10^{\circ} \mathrm{C}$ 에 저장하였다. 저장 중 이자벨, 카이피라의 중량감소가 가장 높았던 반면, 버터 헤드 중량감소가 가장 낮았고, 클로로필 힘량은 미니로메 인이 가장 높았다. 저장 18 일 동안 버터헤드의 신선도가 가장 오래 유지되었고, 이자벨, 파게로, 미니로메인 그리고 카이피라는 저장 12 일 동안 선도가 유지되었다. PET 용기 로 포장된 버터헤드는 품질 유지에 효과적이었으며, $\mathrm{PP}$ 


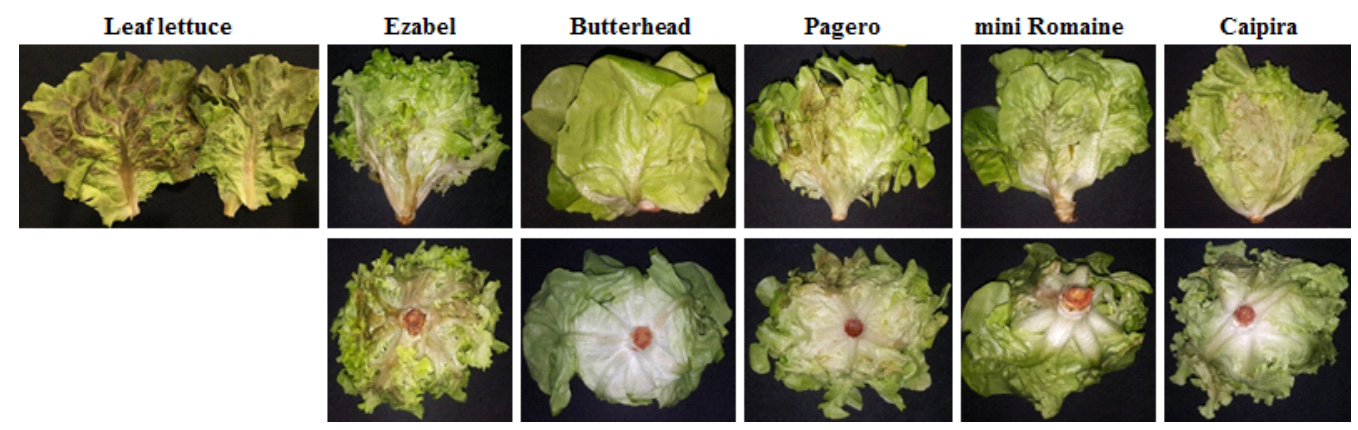

Fig. 5. Changes in the appearance of lettuces by packaging types during 18 days at $10^{\circ} \mathrm{C}$.

필름으로 포장된 상추들은 물러짐과 변색이 빠르게 진행 되었다. 또한, 잎 너비가 넓을수록 선도유지 기간이 길었으 며 잎 너비가 좁을수록 선도유지 기간이 짧았다. 본 연구를 통해 상추 종류별 선도유지를 위해 최적의 맞춤형 $\mathrm{MA}$ 포장방법을 개발할 필요가 있다고 판단된다.

\section{감사의 글}

본 연구는 농촌진흥청 시험연구사업(과제번호: PJ0150 29012020)의 지원을 받아 수행되었습니다.

\section{Conflict of interests}

The authors declare no potential conflict of interest.

\section{ORCID}

Min-Sun Chang https://orcid.org/0000-0002-3079-8338

\section{References}

Bae JM, Lee DU, Jeong MC, Choi JH. Change of quality characteristics in fresh-cut 'Romaine' lettuce by heat treatment. Korean J Food Preserv, 23, 27-33 (2016)

Bark DE, Yoon YN, Woo YJ, Cheung GH, Hwang SB, Park SH, Woo YJ, Shin C, Choi DS, Lim JH, Park SE, Lee JS. Freshness comparison of lettuce (Lactuca savita L.) in accordance with storage and packaging method on high-temperature period. J Korea Soc Packag Sci Tech, 21, 35-40 (2015)

Chang MS, Lee JS. Effects of packaging methods on the freshness during storage of lettuce harvested in summer season of Korea. Korean J Food Preserv, 24, 159-167 (2017)
Hong JH, Lee HS, Jeong HG, Hwang SJ. Current status of breeding and plant new variety protection of lettuce in Korea. Hort Sci Technol, 10 (Supplement II), 67 (2007)

Hong JH, Kwon YS, Choi KJ, Mishra RK, Kim DH. Identification of lettuce germplasms and commercial cultivars using SSR markers developed from EST. Kor J Hort Sci Technol, 31, 772-781 (2013)

Hwang SJ, Jang SW, Choi JH, Ho QS. Selection of standard example varieties for evaluation of plant morphological characters in DUS test of lettuce (Lactuca savita L.). Kor J Hort Sci Technol, 21, 181-189 (2003)

In BC, Kim JG. Effect of precooling and harvesting at different times on respiration, browning and microbial growth of fresh-cut iceberg lettuce. Kor J Hort Sci Technol, 26, 258-264 (2008)

Jang SW, Choi HS, Yang EY, Lee JN, Cheon MH, Park JH, Um MJ, Lee BJ, Ko SB. Breeding of new type red butterhead lettuce 'Sunny Red Butter'. Korean J Breed Sci, 49, 87-91 (2017)

Jang SW, Lee EH, Kim WB. Analysis of research and development papers of lettuce in Korea. Kor J Hort Sci Technol, 25, 295-303 (2007)

Jeong CS, Park SM, Kang WH. Effects of charcoal-added functional paper on keeping leafy lettuce fresh during marketing. Kor J Hort Sci Technol, 21, 102-105 (2003)

Jeong CS, Um GJ, Park JN. Accumulation of off-flavor compounds and quality change in modified atmosphere packaging of leafy vegetables. J Agric Life Environ Sci, 23, 1-7 (2011)

Kim JG, Choi JW, Park MH. Effect of different days of postharvest treatment and $\mathrm{CO}_{2}$ concentrations on the quality of 'Seolhyang' strawberry during storage. Korean J Food Preserv, 23, 12-19 (2016)

Kim TS, Jang YH, Kim JH, Park EJ, Jang SW. A survey 
on preferences of the elementary school students and teachers for the lettuce varieties circulated in Korean fresh vegetable markets. Hort Sci Technol, 35), 122-123 (2017)

Kristkova E, Dolezalova I, Lebeda A, Vinter V, Novonta A. Description of morphological charactersof lettuce (Lactuca savita L.) genetic resources. Hort Sci (Prague), 35, 113-129 (2008)

Lee JS, Choi JW, Chung DS, Lim CI, Seo TC, Do GL, Chun CH. Effects of lettuce (Lactuca savita L.) cultivars and cultivation methods on growth, quality, and shelf-life. Kor J Hort Sci Technol, 23, 12-18 (2005)

Lee JS, Chung DS, Choi JW, Jo MA, Lee YS, Chun CH. Effects of storage temperature and packaging treatment on the quality of leaf lettuce. Korean J Food Preserv,
13, 8-12 (2006)

Lee JS, Chung DS, Lee JU, Lim BS, Lee YS, Chun CH. Effects of cultivars and storage tempertures on shelf-life of leaf lettuces. Korean J Food Preserv, 14, 345-350 (2007)

Ma L, Dolphin D. The metabolites of dietary chlorophylls. Phytochemistry, 50, 195-202 (1999)

Ministry for Food, Agriculture, Forestry and Fisheries (MAFRA). The Statistics of Vegetable Production. Korea, p 11 (2016)

Whitaker TW, Ryder EJ, Rubatsky VE, Vail PV. Lettuce Production in the United States US. Dept. Agric. Handbook 221, p 6-13 (1974) 